\title{
Os homens da Igreja, de Darwin e da ficção científica - Relações entre ciência e religião retratadas na literatura do século XIX britânico
}

Vitor da Matta Vívolo

\section{Resumo}

O século XIX britânico, responsável pela construção da figura reclusa do pesquisador de laboratório e dos polêmicos embates entre criacionismo e darwinismo, possui como parte de sua gênese social a exegese da criação do mundo e da humanidade. O presente artigo, através de relatos de época e abordagem dialógica, realiza uma leitura comparada entre teólogos e cientistas vitorianos no campo de debate ideológico concernindo Deus e as leis da Natureza. Também perpassa o criacionismo e darwinismo como impacto científico e moral em obras literárias (mais especificamente em Frankenstein, de I8I8, por Mary Shelley; e A ilha do dr. Moreau, de I896, por H. G. Wells), buscando compreender como permanecem culturalmente construções bioéticas que datam cerca de duzentos anos atrás.

Palavras-chave: Darwinismo - Ficção Científica - Século XIX - Criacionismo - Era Vitoriana. 
Diante de atuais e acalorados debates entre religião e ciência acerca de células-tronco, clonagem, transplante de órgãos ou até mesmo métodos abortivos, muitas vezes nos sentimos parte de uma dimensão histórica completamente nova e particular: os avanços científicos contemporâneos seriam relegados à resistência de instituições e práticas sociais de tempos passados em um contexto nunca antes compartilhado por ambas as áreas do conhecimento supracitadas. No entanto, ao nos posicionarmos de tal forma, parecemos esquecer que, há cento e cinquenta e cinco anos atrás, o divórcio entre religiosos e cientistas foi marcado por uma obra em particular: A origem das espécies de Charles Darwin.

O século XIX britânico foi responsável pela construção da figura melancólica, dicotômica e reclusa do pesquisador de laboratório. Não apenas uma classe profissional, mas intelectual, essa parcela da sociedade criou-se e desenvolveu-se imersa nas morais e nos dogmas religiosos de sua época. Mesmo antes do termo "cientista" ser cunhado por volta de I830, um senso de coletividade de valores e preocupações surgiu entre os produtores dos "conhecimentos naturais" (derivados da história natural e da filosofia natural), juntamente a uma epistemologia em comum. Aos envolvidos com medicina existia uma possibilidade maior de renda fixa e afiliações institucionais honorárias. Mesmo assim, pode-se observar a falta de poder homogêneo entre doutores até a regularização das escolas de anatomia. À figura do "cientista", em termos mais amplos que os medicinais, restava pouca estabilidade. Até a metade do século, a atividade do estudante de ciência natural era muito mais ligada ao ramo clerical ou virtudes estoicas e ao mundo de estudos clássicos. Visto como um hobby para amadores, o conhecimento científico ainda era encarado como exclusivamente útil a poucas profissões. Thomas Huxley, ainda jovem e no início de sua carreira, escreveu para sua irmã:

Não há chance de se viver de ciência. Estava relutante em acreditar, mas é verdade. Não existem mais do que quatro ou cinco cargos em Londres no qual um zoologista ou anatomista comparativo pode tomar e viver deles. Owen, que tem uma reputação europeia, perdendo apenas para Cuvier ${ }^{\mathrm{I}}$, paga a um Hunterian Professor 2300 libras por ano! que é menos que o salário de muitos caixas de banco (HUXLEY apud IRVINE, I955, p. 27).

I Richard Owen (I804-I892), famoso biólogo, anatomista e paleontólogo. Georges Cuvier (I769-I832), naturalista e zoólogo francês, famoso por estabelecer anatomia comparativa entre animais vivos e fósseis. 2 "Hunterian Professor" era o importante título dado aos professores de anatomia contratados pelo Royal College of Surgeons anualmente. O título é em homenagem a John Hunter (I728-I793), colecionador e estudioso cirúrgico. Seu museu foi adquirido pela instituição em I799 e muitas demonstrações anatômicas foram executadas dentro dele. 
Os cargos para professores eram ainda mais concorridos, pois quase nem existiam. Numa época em que os materiais de trabalho (leia-se: cadáveres humanos a serem dissecados) eram escassos e mal regulados, é coerente tamanha desorganização em torno de um ramo de profissão ascendente. Como se não fosse suficiente, a possibilidade de casamento podia piorar ainda mais a carreira de um cientista. Gerta vez, Darwin, parabenizando Huxley por sua nova esposa, disse esperar que o casamento não o fizesse indolente, pois "a felicidade", temia, "não era boa para o trabalho" científico (DARWIN apud IRVINE, I955, p. 33).

As áreas do conhecimento relacionadas aos homens da ciência do XIX orbitavam entre história natural, filosofia natural e teologia natural. A primeira era responsável pela classificação sistemática de elementos da Natureza (plantas, animais, estrelas, seres humanos...), a segunda estudava as leis através das quais a Natureza se movimentava e agia (cf. SMITH, in BANN, I994, p. 4I); e a última utilizava as evidências obtidas pelas anteriores para comprovar a existência de Deus e sua bondade (cf. COSSLETT, 2008, p. 2). Aproximadamente uma década após a metade do século, acreditava-se que a teologia natural era a tentativa mais bem-sucedida de conciliar ciência e religião (Idem, 2008). Até a publicação de A origem das espécies, em I859, as descobertas científicas eram majoritariamente observadas como revelações da ordem e desígnios divinos.

William Paley, apologista cristão, publicou, em I802, Natural theology, or evidences of the existence and atributes of the deity ("Teologia natural, ou evidências da existência e atributos da deidade"). Crente da felicidade inerente à Natureza, propagou a famosa imagem do Deus arquiteto, utilizada por teólogos naturais ao longo do século. Sua analogia era estabelecida ao imaginarmos nosso encontro ocasional com uma pedra ou um relógio: o primeiro poderia fazer refletir sobre a casual origem do objeto, o segundo nos faria admitir a incontestável presença de um diligente ourives para sua existência.

Nos campos da geologia, no entanto, o Deus engenheiro parecia não ter planejado diretamente seus projetos. Desde o século XVII, o arcebispo Ussher datou - através das escrituras - a criação do mundo em 4004 a. C. e assim foi estabelecida a acepção numérica oficial da Igreja em relação ao gênese. O problema era que as evidências fornecidas por fósseis descobertos por geólogos pareciam contrariar os cálculos cristãos. Além disso, o naturalista francês Jean-Baptiste Lamarck pregava, na década de I820, haver provas de que as espécies animais possuíam um desenvolvimento de diferentes características adquiridas desde a criação do mundo até sua contemporaneidade. Esse primeiro rascunho de teoria evolutiva, estabelecendo "degraus" de uma escada 
de progresso biológico ao longo da história, era incompatível com um Deus pré-planejador e engenheiro perfeito do universo.

Mesmo descrente das teorias evolutivas de Lamarck, Charles Lyell, geólogo, colaborou ainda mais para a confusão de mentes científicas ao redor da gênese. Nos anos 30 do século XIX, publicou Os princípios de geologia: constituindo uma tentativa de explicação das antigas transformações da superfície da Terra pela referência a causas ora atuantes, partindo de uma premissa de que apenas admitia a evidência de forças geológicas nos estudos da idade terrestre, desconsiderando materiais bíblicos como fontes de referência concreta. A Terra agora possuía, então, uma sucessão indefinida de idades, cada uma correspondendo a uma camada geológica encontrada. O campo religioso reagiu através do "catastrofismo", teoria que via cada diferente idade como uma série de "criações" divinas. Dentro de seus argumentos, apontavam provas como o dilúvio de Noé ou os "seis dias" de criação do Gênesis, sendo uma metáfora para seis eras geológicas distintas.

O debate entre religião e a ciência do século XIX é, portanto, uma relação de forças não necessariamente contrárias. A problemática era muito mais uma questão entre ciência religiosa e ciência em busca de laicização, ao invés de uma ciência ateia contra uma religião dogmática e inconciliável. Essa apropriação de discursos entre ambas as áreas fica clara em mitos de criação tipicamente fantásticos na literatura da época como Frankenstein, ou O Prometeu moderno (I8I8, de Mary Shelley), primeiro romance fictício-científico a ser escrito - a famigerada lenda do médico alinhavador e reanimador de peças cadavéricas - e vivo até hoje através do arquétipo do monstro verde plagiocefálico com eletrodos no pescoço. Ou até mesmo nas obras de H. G. Wells, famoso autor de ficção científica, criador dos livros A máquina do tempo (I895), sobre o cientista capaz de viajar ao futuro e se posicionar introspectivamente no fim evolutivo da raça humana, e $A$ ilha do dr. Moreau (I896), romance de terror ao redor da estação biológica de experimentação de um médico capaz de transformar animais em homens através de transplantes e procedimentos de lavagem cerebral.

É importante rememorarmos que dr. Frankenstein ${ }^{3}$, como filho de Adão, pela primeira vez na mitologia de criação (considerando uma comparação com lendas de mitologias anteriores, como o deus grego Asclépio, ou até mesmo

3 "Frankenstein" é o sobrenome do criador do monstro, Victor Frankenstein. Sua cria não possui nome e é sempre referida por termos pejorativos como "demônio", "aberração", "bastardo" etc. 
o mito hebraico de rabino Loew $^{4}$ ) deixa claro que sua metodologia criativa é relacionada com a própria metodologia científica. Sua descoberta do segredo da vida e da morte é resultado de suas pesquisas em cadáveres e estudos nos ramos intelectuais da ciência e não da teologia. Apesar disso, a influência da última atinge a moralidade de sua história, como indireta refração advinda da vida de sua autora.

Vejamos a cena que precede a geração de vida na criatura:

A princípio fiquei em dúvida sobre se deveria tentar criar um ser igual a mim, ou uma criatura mais simples; mas minha imaginação estava por demais exaltada pelo sucesso já alcançado para permitir que eu duvidasse de minha habilidade de dar vida a um animal tão complexo e maravilhoso como o homem. [...] Como a excessiva minúcia das partes constituía obstáculo a me atrasar, resolvi, contrariamente a minha intenção anterior, fazer um ser de estatura gigantesca, ou seja, tendo em torno de dois metros e meio de altura, e o resto do corpo proporcional. Depois de ter assim decidido e ter passado alguns meses coletando e organizando com sucesso o material necessário, iniciei o trabalho.

É impossível alguém imaginar o tumulto de sentimentos que me impulsionava, feito um furacão, tanto o sucesso inicial me entusiasmava. A vida e a morte não eram para mim mais que limites imaginários, e eu seria o primeiro a rompê-los, inundando de luz nosso mundo sombrio. Uma nova espécie iria me abençoar como seu criador e origem; vidas felizes e brilhantes deveriam sua existência a mim. Nenhum pai poderia ter a gratidão de seus filhos tão completamente como a que eu mereceria. Indo mais longe nessas reflexões, eu pensava que, se eu era capaz de dar vida à matéria inerte, com o tempo poderia (embora ache agora impossível) renovar a vida onde a morte aparentemente condenara o corpo à decomposição (SHELLEY, 2006, p. 6I-62).

A possibilidade primeira de criação de seres "mais simples" como os animais, seguida do ser "maravilhoso e complexo" como o homem por si só já remete à ordem estabelecida na criação bíblica. Também a capacidade de dar vida à "matéria inerte" de um "ser de estatura gigantesca" nos remete ao "barro disforme" inicial de Adão que pode ser animado por Deus e se tornar um homem. O criador frankensteiniano seria o portador da vitória da vida sobre a

4 Asclépio é o deus grego da medicina, capaz de controlar a mortalidade dos seres. Loew faz parte de uma fábula judaica do século XVI, o "Golem", na qual um rabino cria um homem de barro e lhe dá vida. 
morte; mas como isso se deu através de uma ciência galvânica e alquímica (métodos não divinos), até possivelmente ocultista, torna-se a penitência divina ou a nêmesis - a vingança mitológica grega - de seu criador. Mary Shelley, da mesma forma que a ciência do início do século XIX, não abdicou da sombra das crenças cristãs sobre a moral de sua obra.

O discurso científico do século foi radicalmente modificado graças a Darwin que, da mesma forma que Lyell (aliás, era leitor de sua obra), buscou "explicar o que anteriormente era pensado como miraculoso em termos de gradualismo e causalidades naturais" (COSSLETT, 2008, p. 7). No mesmo período em que o pensamento religioso passava por uma crise interna entre seus membros devido às controvérsias relacionadas ao criticismo bíblico, poderia a Bíblia ser realmente estudada como um documento histórico? Se sim, de que forma se lidaria com sua autoria múltipla e suas diversas versões, muitas vezes dicotômicas, de mesmos fatos e acontecimentos? "Pensar em evolução era", inevitavelmente, "pensar em criação e imutabilidade" (IRVINE, I955, p. 5I). As questões incitadas por Darwin estavam relacionadas não só com a natureza, mas a Deus, à Bíblia e com a ética e moral vitorianas.

A vida de Charles Darwin teve relações sempre muito próximas com a questão do divino: quando jovem, após suas experiências iniciais mal sucedidas com a medicina, seu pai o enviou para um colégio religioso a fim de estudar e se tornar pároco. Foi lá que Darwin teve seu primeiro contato com a história natural e elementos de botânica, sendo logo indicado como pesquisador $^{5}$ a bordo do HMS Beagle. Na viagem, tomou contato com dados geológicos e biológicos que o fizeram, ao longo de vinte anos, elaborar sua teoria evolutiva. Influenciado também pela obra de Thomas Robert Malthus, que pregava a eminente futura fome populacional devido ao crescimento geométrico da população versus o aritmético de alimentos, pôde ver na natureza a sua "economia": uma eterna luta pela sobrevivência entre os seres. Também retomou as leituras das obras de seu avô, Erasmus Darwin, um dos primeiros a elaborar teorias (em verso) sobre a mutabilidade dos seres, juntamente às elucubrações de Lamarck.

Quando sua obra foi publicada, invadiu terreno religioso de forma nunca antes presenciada: o impacto da afirmação de leis naturais, a la Newton, pressupondo um criador de mecanismos no universo, era completamente diferente

5 Era costume enviar um estudante de história natural a bordo de navios que fariam longas viagens a fim de se coletar espécimes e dados botânicos e biológicos das terras que seriam visitadas. 
daquele de se enxergar uma força que por caprichos próprios e incontroláveis regia o mundo natural. A seleção natural não "representa uma harmonia, mas um conflito, e se dá não por um preciso, matemático, idealismo de uma força invisível, mas, aparentemente, por um cruel, arbitrário sorteio de variações feito pelo ambiente" (IRVINE, I955, p. 97). A vida, de forma cega, se reproduzia, batalhava e provocava sua carnificina a fim de atingir a mente e racionalidade do topo evolutivo.

Contemplamos a natureza exuberante de beleza e de prosperidade e notamos, muitas vezes, uma superabundância de alimentação; mas não vemos, ou esquecemos, que as aves, que cantam empoleiradas descuidosas num ramo, se nutrem principalmente de insetos ou de grão, e que, fazendo isto, destroem seguidamente seres vivos; esquecemos que as aves carnívoras e os animais de presa estão à espreita para destruir quantidades consideráveis desses alegres cantores, destruindo-lhes ovos ou devorando-lhes os filhos (...) (DARWIN, 2002, p. 69).

Entretanto, sua maior "blasfêmia" foi traçar um ancestral comum entre todos os homens e animais. Uma das ramificações desse tronco de parentesco era o macaco. Em uma das discussões mais famosas da história do darwinismo, o bispo Willberforce perguntou a Huxley, o ávido defensor das teorias de Darwin, se era "por parte de avô ou de avó que clamava sua descendência do macaco", fazendo com que todos os presentes no simpósio caíssem na gargalhada. Huxley, após um inflamado discurso em defesa de suas próprias crenças científicas, disse que não se envergonharia de ter um macaco como ancestral, mas, sim, de possuir um homem que utiliza seus dons para encobrir a verdade. A sensação foi tão imensa que a plateia imediatamente "se converteu" a Huxley, martirizando o bispo e fazendo uma dama dramaticamente desmaiar de horror (IRVINE, I955, p. 6). Darwin pode ter causado alvoroço intelectual, porém, Huxley fez história com ele.

Apesar de a Inglaterra estar madura, ela estava terrivelmente despreparada para a Origem. [A obra] se levantou frente à mentalidade nacional como o fantasma de Banquo terminando a cena do longo banquete da interpretação da década. Inevitavelmente, ela deslocava a analogia da natureza para o homem e se tornou uma espécie de anti-Bíblia. E da mesma forma que a Bíblia por si só foi tomada por muito tempo como um tratado biológico e geológico, a Origem se transformou em um tratado sobre religião e ética, eventualmente política e sociologia (IRVINE, I955, p. I07). (Grifos meus) 
São a ética, religião, política e sociologia da "anti-Bíblia" os elementos fundamentais presentes nas criações fictício-científicas do ramo literário vitoriano. A refração de tais temas fica explícita em personagens como dr. Moreau do supracitado romance de H. G. Wells. O grau de parentesco entre os seres vertebrados é o ponto inicial da metodologia moreauniana: o médico se pergunta quais são os elementos nevrálgicos essenciais para que se possa reproduzir em laboratório toda a força evolutiva. Diferentemente de dr. Frankenstein, seu controle sobre a vida se dá não pela manipulação da reversão da morte, mas, sim, através da capacidade de controlar e incitar o potencial evolutivo de cada ser animal na cadeia progressiva que gerou a humanidade. Moreau, então, é o detentor da reprodução artificial das leis arbitrárias da Natureza.

Utilizando a vivissecação, pratica procedimentos de transplante e modificação orgânica, moldando suas crias não do barro ou de fragmentos mortos, mas dos tecidos e organismos em plena vida. Crê que os procedimentos cirúrgicos de incisão e amputação são meras conquistas triviais da medicina de sua época, pois "na cirurgia existem também os processos de construir, além dos de reduzir e extirpar" (WELLS, 20I2, p. 94). A plasticidade da carne no campo medicinal é o que Wells projetou como o futuro do estudo científico e ferramenta de trabalho de seu protagonista. É alterando a anatomia e fisiologia dos seres "mais simples" (como dizia Frankenstein) que Moreau desperta o gatilho interior de cada animal rumo à constituição do homem.

O doutor deseja trabalhar com a modelagem evolutiva, transformando uma espécie de ser em outra. Ao contrário de Frankenstein, a figura humana é selecionada por um mero acaso. Apesar disso, "existe algo na forma humana que atrai nossa mentalidade artística de modo mais poderoso do que uma forma animal qualquer" (WELLS, 20I2, p. 97). Sua sabedoria e pesquisas apontam que o que pertence à humanidade vai além da mera quantidade de membros e proporções físicas. O médico encontra outra lei existente na $\mathrm{Na}-$ tureza: a dor. E é nesse delicado aspecto que é julgado por Prendick, o visitante indesejado em sua ilha devido a um naufrágio, e acusado de crueldade sob a ótica de preceitos cristãos. Sua defesa é incisiva:

Além disso, sou um homem religioso, Prendick, como qualquer homem equilibrado. Penso que investiguei os desígnios do nosso Criador melhor do que você, porque mergulhei no estudo de suas leis, enquanto você, pelo que sei, colecionava borboletas. E vou lhe dizer, prazer e dor não têm nenhuma relação com o céu e o inferno. Prazer e dor... bah! O que são os êxtases dos teólogos, senão as huris prometidas por Maomé? A importância que homens e mulheres dão 
ao prazer e à dor, Prendick, é a marca do animal ${ }^{6}$ sobre eles, a marca do bicho que um dia fomos. Dor! Dor e prazer... existem para nós apenas enquanto nos espojamos no pó (WELLS, 2012, p. 98).

A ironia de Wells é marcante: Moreau, "um homem religioso", está mais próximo de entender o divino do que muitos daqueles que se julgam crentes. Prendick, com todo o seu moralismo vitoriano, se detém, assim como os teólogos naturais e mais profundos conhecedores das escrituras, no papel de observador da criação, "colecionando borboletas". Moreau, da mesma forma que Darwin, não só contempla "a natureza de exuberante beleza", como adentra seus mecanismos e compreende suas leis. Assim, no romance de Wells, Moreau, o evolucionista vivissecionista, é mais eficaz religiosamente do que Prendick, o cristão estudioso da história natural. Além disso, o conceito de pecado é deslocado para uma trivial marca de um conceito evolutivo prestes a ser ultrapassado pela própria natureza. Marca essa, "dor e prazer", que é o ponto de mutação explorado pelo dono da ilha em laboratório.

Ainda ao ser questionado em relação à ética de seus procedimentos, o doutor se defende de moralismos colocando-se no lugar de seu terreno de pesquisa: "até hoje a questão ética deste meu trabalho não me preocupou, em absoluto. O estudo da natureza deixa um homem tão despido de remorsos quanto a própria natureza" (WELLS, 20I2, p. 99). O argumento de Moreau é interessantemente similar a uma metáfora utilizada por Huxley em uma de suas cartas a um religioso. Ao ser questionado sobre a existência do divino, Huxley compara o universo e suas leis a uma partida de xadrez.

O tabuleiro de xadrez é o mundo, as peças são os fenômenos do universo, as regras do jogo são o que chamamos de leis da Natureza. O jogador do outro está oculto para nós. Sabemos que suas jogadas são sempre honestas, justas e pacientes. Mas também sabemos, a nosso próprio custo, que ele nunca negligencia um erro ou dá o menor aval para ignorância. Ao homem que jogar bem, as maiores apostas são pagas, com aquele tipo de generosidade transbordante com a qual o forte demonstra prazer na força. E aquele que jogar mal leva o cheque-mate sem pressa, mas também sem remorso (HUXLEY apud IRVINE, I955, p. I30).

6 "Mark of the beast" no original. Trocadilho entre a "marca da besta", ou seja, sinal de relação com o demoníaco, e a marca da animalidade ancestral de cada humano na escala evolutiva. A tradução de Bráulio Tavares não mantém este sentido. 
Moreau talvez seja, assim como Huxley, não um ateu, mas um agnóstico. É incapaz de conhecer a real face do outro jogador na mesa, então reconhece sua existência sem ousar determinar se é uma força ou divindade. Também enxerga a religiosidade na ciência como uma substituta eficaz e de mesmo valor para a religiosidade teológica. Sua crença nos métodos de pesquisa o torna um bom jogador que espera ser recompensado. Da mesma forma, visa reproduzir essa ordem do cosmos em suas criaturas: na mesa de cirurgia, sem pressa, o cheque-mate virá caso seja necessário... e sem remorso algum.

Se a salvação do corpo ou da alma constitui a própria corda cuja tensão reside entre cientistas e religiosos há cerca de dois séculos, permanece relevante a teoria huxleiana do agnosticismo seguida por Moreau: a incontestável predileção pela ciência não tornaria os próprios cientistas devotos de alguma causa tão religiosamente forte quanto a própria divindade bíblica?

A absorção das dicotomias no contexto científico de época pelos romances é completamente válida perante a especulação de que o contato inicial do chamado "público leigo" com a emergência científica dava-se não só por meio dos jornais e comentários nas ruas, mas também pelos desdobramentos das mentes fantasiosas de autores de ficção. Ao escritor cabia a liberdade de espelhar não somente as potencialidades científicas, mas os medos pinçados na própria cultura cristã das massas ditas "populares".

Aos membros da academia jamais era aceito "especular", utilizando somente metodologias imaginativas, principalmente após a disseminação da cultura laboratorial de se exigir resultados universais na aplicação de toda teoria. Fórmulas e conhecimentos, à época, só eram científicos quando se provavam incontestáveis perante a experimentação. Desta forma, aos "leigos", ou seja, todos aqueles que não se inseriam nos estudos da ciência, cabia não só a luta diária pela sobrevivência no processo civilizatório, mas também o desdobramento criativo dos temores e expectativas tecidos por mentes fascinadas perante os milagres roubados dos céus pelos homens de aventais brancos.

\section{Conclusão}

A hierarquia social vitoriana crescia e fazia emergir as classes médias, convenientemente localizadas como "acolchoado" entre a inatingível cultura da elite e os "reprimíveis costumes selvagens" da pobreza. Nessas condições de intermédio, nascem figuras como Mary Shelley ou H. G. Wells, escritores capazes de fazer a ponte entre a linguagem acadêmica e a inventividade popular. Ao público leitor, tão acostumado com romances sensacionalistas de 
violência e sangue ${ }^{7}$, é terrivelmente assustadora a consciência de que em breve poderiam viver em um mundo como aqueles das páginas de ficção científica: capaz de gerar seres inescrupulosos como tais doutores frente à imagem de Deus. Ironicamente, a figura do "cientista louco" continua viva até hoje como herança cultural do embate: a quem pertence controlar a mortalidade, a velhice ou a doença?

Os autores de ficção, reduzidos geralmente à mera crítica literária, podem ser lidos e convidados a representar não somente portadores criativos de obras imaginativas, mas sujeitos críticos submersos na complexa rede sócio-histórica construída por embates culturais de seus contextos passados. Suas vidas, suas leituras, suas companhias, sua educação, suas crenças, seus estudos... Todos fazem parte da gênese de suas obras, pois, atrás de uma trama, existe um narrador; atrás de um narrador, existe um autor que lança suas visões tanto sobre suas próprias personagens, quanto o mundo no qual vive.

Mundo este, em nosso presente recorte histórico, imbuído de curiosidade em relação à própria gênese dos corpos humanos e da humanidade. Os agentes do progresso deixaram gradualmente de ser os retóricos da escolástica, a Bíblia perdeu o seu caráter documental científico e passou a duelar por espaço de autoridade com aqueles capazes de ler as lógicas do Universo.

Infelizmente, trabalhar com a história é conhecer suas vertentes seguintes sem nenhum tipo de suspense. Sabemos então que as teorias darwinistas, tão marcantes pelo divórcio com o pensamento religioso, terminaram por serem lidas no futuro através de óticas autoritárias tão irredutíveis quanto a força representada pelo pensamento bíblico fervoroso de outrora... E assim tornaram-se o embasamento teórico medicinal "irrefutável" - leia-se "comprovado por estudos científicos" - de práticas racistas e higienistas do final de sua época até meados do século XX nos campos de concentração nazistas.

É-nos interessante, no entanto, perceber que nossa modernidade foi influenciada pela ciência não só nos campos tecnológicos, mas nos culturais. É nesses âmbitos que buscamos a literatura como comunicação com um passado distante e rastreamento das permanências de suas mentalidades. Se hoje em dia filmes de terror com corpos sendo suturados por médicos insanos são sucessos de bilheteria ou crianças buscam se vestir como a criatura verde com eletrodos no pescoço da famosa adaptação do romance de Mary Shelley

7 Os chamados penny dreadfuls, revistas sobre contos e notícias inventadas de assassinatos, altamente comercializados nas classes médias e baixas. Histórias como a de Sweeney Todd tiveram sua origem nessas publicações de custo acessível: um penny. 
com Boris Karloff, resta-nos perguntar até que ponto os mitos literários de uma era tão distante não terminaram por ser refratados ao longo dos anos e permanecem vivos na realidade de nossos inconscientes ao pensarmos o que é "ciência".

Estratégias biomédicas atuais continuam na permanente busca de princípios éticos para a realização de seus intentos, e à Igreja remanesce um discurso dentro de parâmetros similares. $O$ contraste de posicionamento frente à valorização do cientificismo é gritante um século depois, mas com fatores em comum: ética e consequência.

Tanto nos edifica no trabalho científico - nos edifica e também nos alegra profundamente - esta marcha do conhecimento desinteressado da verdade a que o sábio se dedica com o maior empenho e às vezes com risco da saúde e mesmo da vida, quanto deve preocupar-nos tudo o que está em contradição com os princípios de desinteresse e de objetividade, tudo o que fizesse da ciência um instrumento para atingir finalidades que nada têm que ver com ela. Sim, nós devemos preocupar-nos com tudo o que propõe e pressupõe somente estas finalidades não científicas exigindo homens de ciência que se coloquem ao serviço dessas finalidades sem lhes permitir julgar e decidir, com toda a independência de espírito, sobre a honestidade humana e ética das mesmas, ou ameaçando-os de sofrer as consequências quando recusam contribuir para o que se pretende (Discurso de João Paulo II na sede da Organização das Nações Unidas para a Educação, Giência e Cultura - Unesco. Paris, 2 de junho de I980. Disponível em: http:// www.vatican.va/holy_father/john_paul_ii/speeches/Ig8o/june/documents/hf_jp-ii_spe_I9800602_unesco_po.html. Acesso em: 29/05/I4).

Sejam as escrituras ou tubos de ensaio que regem esta "marcha pela verdade humana", é intrigante sabermos que ainda não encontraram resultado consonante perante o enigma da vida e da mortalidade dos homens. Sejam eles as progênies modernas dos anjos ou dos macacos, de futuros drs. Frankensteins ou Moreaus.

\section{Referências bibliográficas}

BANN, Stephen, Frankenstein creation and monstrosity. I ${ }^{\underline{a}}$ ed. Oxford: Reaktion Books, I994.

COSSLETT, Tess. Science and religion in the nineteenth century. $2^{\underline{a}}$ ed. Nova York: Cambridge University Press, 2008. 
DARWIN, Charles. A origem das espécies e a seleção natural. 5ª ed. São Paulo: Hemus, 2002.

IRVINE, William. Apes, angels and victorians. $\mathrm{I}^{\underline{a}}$ ed. Londres: Weidenfeld and Nicolson, I955.

SHELLEY, Mary. Frankenstein. Iํㅡㄹ ed. São Paulo: Editora Ática, 2006.

WELLS, H. G. A ilha do dr. Moreau. I⿳亠丷厂 ed. Rio de Janeiro: Objetiva, 2012.

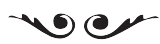

Vitor da Matta Vívolo - Graduado em História pela Pontifícia Universidade Católica de São Paulo em 20I4. Mestrando em História Social pela Pontifícia Universidade Católica de São Paulo.

vitorvivolo@gmail.com. 